\title{
Does gonorrhoea surveillance pay?
}

\author{
ROBERT C. RENDTORFF AND HENRY PACKER \\ From the Departments of Community Medicine and Microbiology, University of Tennessee Center for the \\ Health Sciences, and the Memphis-Shelby County Health Department, Memphis, Tennessee, USA
}

\section{Introduction}

In previous studies which emphasised the role of the urban community hospital in gonorrhoea surveillance, the effectiveness of the communitywide screening programme in reducing serious complications of the disease in women has been stressed (Rendtorff et al., 1976, 1977). While the rate of gonorrhoea has remained essentially at the same level during the past four years, the incidence of pelvic inflammatory disease and salpingitis among patients admitted to the City of Memphis Hospital has shown a marked decline since the surveillance programme was set up in MemphisShelby County, Tennessee, in 1968.

'It is conceivable that a continuing surveillance programme for gonorrhoea in women, reaching a large segment of the population at risk, may have no impact upon the infection rate, which is primarily a behavioural problem, but it may nevertheless stop the infection from progressing to pelvic inflammatory disease by treating early infections' (Rendtorff et al., 1977). This suggestion that a surveillance programme might be successful in reducing the incidence of complications of gonorrhoea in women prompted us to look further into the situation in Memphis.

\section{Incidence of PID and salpingitis}

There are four central city hospitals in Memphis, and data on the incidence of pelvic inflammatory disease and acute and chronic salpingitis were obtained from each hospital. These conditions are often gonococcal in origin, as previous studies have indicated (Rendtorff et al., 1974). The number of such cases reported each year from the discharge diagnosis (disease index) for each hospital was divided by the annual number of discharges. These

Address for reprints: Dr R. C. Rendtorff, Department of Community Medicine, University of Tennessee, 800 Madison Avenue, Box GA150, Memphis, Tennessee 38163, USA

Received for publication 15 August 1978 data were then plotted as a three-year moving average of rates of cases per 1000 admissions as shown in the Figure. The biases inherent in these data, especially in the use of the denominator statistic, are well recognised; however, these should be fairly consistent over the years and not markedly affect the slopes of the curves.

Data from two hospitals, City of Memphis Hospital and hospital A, showed a marked decline in the incidence rate of these complications during the period of the study. Figures from two other hospitals, B and C, showed more constant rates for these conditions. To interpret these differences in the rates between the hospitals the characteristics of patients served by each hospital must be examined.

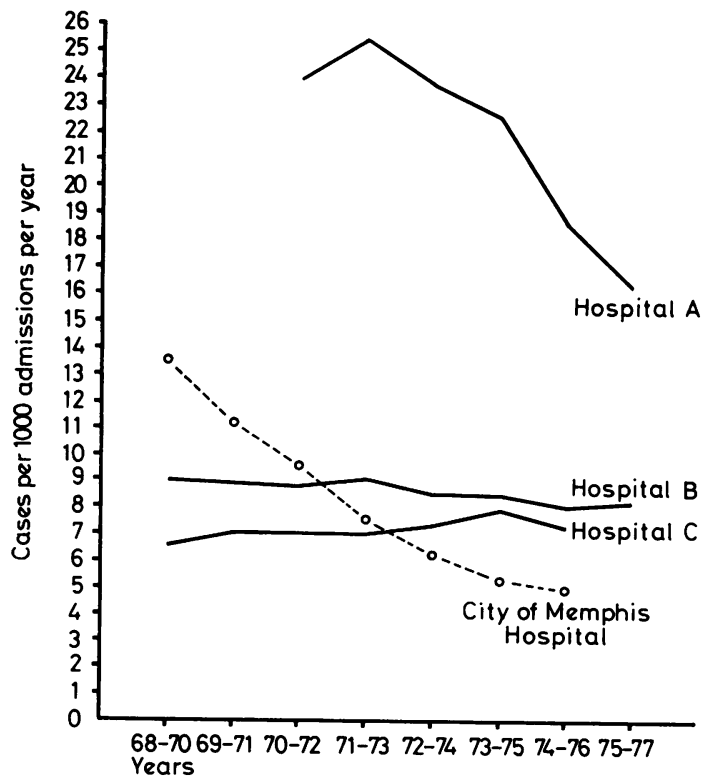

Figure Incidence rate of pelvic inflammatory disease and salpingitis in four Memphis hospitals (by three-year moving average) 
POPULATION GROUPS

The City of Memphis Hospital serves the indigent poor of the city. Only $18 \%$ of its patients live outside the county, and these are from the surrounding metropolitan areas which cross state lines. Hospital A is located in a very low socioeconomic area of the city. Both hospitals serve patients from the indigent to lower socioeconomic levels, the women of which group are very likely to be screened in the surveillance programme, which is carried out intensively among this sector of the population. Statistics from both hospitals showed a marked decline in the rates of complications over the period of the study. The higher rates at hospital A may be due to a greater availability of beds and to its smaller size, which affects the denominator. This private hospital has an excess of beds available, and physicians practising here tend to admit their patients to hospital for treatment. In contrast, the City of Memphis Hospital is a larger, overcrowded university teaching hospital. Beds are at a premium and patients with common conditions, such as pelvic inflammatory disease and salpingitis, are frequently treated as outpatients rather than in hospital. A recent study has shown that only one out of 30 women with pelvic inflammatory disease seen in the city hospital emergency room was admitted.

The two private hospitals, $B$ and $C$, serve an entirely different population of patients; these are of higher socioeconomic status and generally would not have participated in the surveillance screening programme. Of the patients at hospital C $57 \%$ are referred from a seven-state medical catchment area beyond the metropolitan area. Hospital B similarly receives many of its patients by referral from the same area. These two hospitals in effect serve as a control, since their patients are not reached by the screening system and one would not expect the rate of complications to vary over the years.

\section{Conclusion}

The data given in the Figure show the beneficial effects of community-wide screening for gonorrhoea in women. A previous study on the costs of treating gonorrhoea in women has already stressed the vast economic consequences of this disease, not to mention its devastating effects on the lives of those infected (Rendtorff et al., 1974). The social implications of gonorrhoea in this sense must be fully recognised. It is a truly devastating disease in women, and, economically, gonorrhoea surveillance is worthwhile.

\section{References}

Rendtorff, R. C., Curran, J. W., Chandler, R. W., Glassco, S., and Wiser, W. (1976). The role of the urban community hospital in gonorrhoea surveillance. British Journal of Venereal Diseases, 52, 102-104.

Rendtorff, R. C., Curran, J. W., Chandler, R. W., Wiser, W. L., and Robinson, H. (1974). Economic consequences of gonorrhea in women: Experience from an urban hospital. Journal of The American Venereal Disease Association, 1, 40-47.

Rendtorff, R. C., Packer, H., Glassco, S., and Levy, J. S. (1977) The impact of urban community hospital surveillance for gonorrhoea on the infection rate and complications in the female. A progress report. British Journal of Venereal Diseases, 53, 364-367. 